\title{
Fatal cases of lipid storage myopathy with carnitine deficiency
}

F. CORNElio, ${ }^{1}$ S. Di DONATO, D. PEluChetTi, A. BizZi, B. Bertagnolio, A. D'ANGELO, AND U. WIESMANN

From the Institute of Neurology 'C. Besta', the CNR Centre of Cytopharmacology and Department of Pharmacology, University of Milan, and the Mario Negri Institute for Pharmacological Research, Milan, Italy, and the Department of Paediatrics, University of Bern, Switzerland

SUMMARY Three patients affected by a progressive myopathy with rapid lethal evolution are presented. Excessive lipid storage was found in type 1 fibres of muscle and in liver, kidney, and myocardium. Carnitine concentrations were markedly reduced in muscle, plasma, and heart, significantly lower in the liver, and normal in kidney. D-L carnitine replacement therapy was ineffective in the only case treated. The relationship of the present cases with the syndrome of lipid storage myopathy and carnitine deficiency is discussed.

Bradley et al. (1969) first described a young patient with a subacute proximal myopathy and excessive lipid accumulation in type 1 muscle fibres. These authors defined this new pathological condition as lipid storage myopathy and speculated that the lipid accumulation was due to an impaired mitochondrial oxidation of free fatty acids (FFA). Subsequently, Engel et al. (1970) demonstrated in two identical twin girls with lipid storage myopathy, cramps, and myoglobinuria, a defect in the utilisation of long chain fatty acids (LCFA), though medium chain fatty acids (MCFA) seemed to be normal. In another case, Engel and Angelini (1973) could show that in skeletal muscle deficient in LCFA oxidation there was also a marked reduction of carnitine content. In view of the important role of carnitine in the transport of LCFA into mitochondria (Fritz, 1967), carnitine deficiency has been suggested as the primary cause of human lipid storage myopathy (Engel and Angelini, 1973).

The presence of low carnitine levels in other cases with lipid storage myopathy has subsequently been confirmed by others (Angelini et al., 1975; Karpati et al., 1975). We describe here three patients with a lipid storage myopathy, plasma and muscle carnitine deficiency and, as differentiating features, a progressive fatal course and lipidosis in organs other than muscle.

\footnotetext{
'Address for correspondence: Dr F. Cornelio, Neuromuscular Research Laboratory, Istituto Neurologico 'C. Besta', Via Celoria 11, 20133 Milan, Italy.

Accepted 21 September 1976
}

\section{Case 1}

R.E., a 28 year old woman, showed normal psychomotor development until she was 16 years old when she experienced an episode of marked adynamia associated with nausea and vomiting after prolonged? stress, the patient having been lost in the mountains for three to four days without food and shelter, because of a snowstorm. Over the next 10 years she experienced several other spontaneous episodes of adynamia and nausea, lasting three to four days.

At the age of 26 years the patient became pregnant and was in good condition until the last two months when a diffuse muscular weakness of progressive severity developed, so that after delivery she became incapable of walking and was confined to bed. Routine laboratory tests performed at that time were normal with only a tendency to a reduction in blood glucose levels, occasionally as low as $1.7 \mathrm{mmol} / \mathrm{l}$. An EMG showed myopathic features.

At the age of 28 years, physical examination revealed a poorly-nourished, thin woman. Blood pressure was $120 / 80 \mathrm{mmHg}$; liver and spleen were not enlarged. Diffuse weakness and wasting of limb girdles, trunk, neck, and tibioperoneal muscles with bilateral foot-drop were observed. Deep tendon reflexes were depressed. Routine blood analyses including cholesterol and triglycerides, low and high density lipoproteins, were normal. Serum electrolytes were normal except for $\mathrm{K}^{+}$which was between $5.30 \mathrm{mmol} / \mathrm{l}$ and $5.80 \mathrm{mmol} / \mathrm{l}$ in serial determinations. Serum aldolase and CPK activities were slightly 

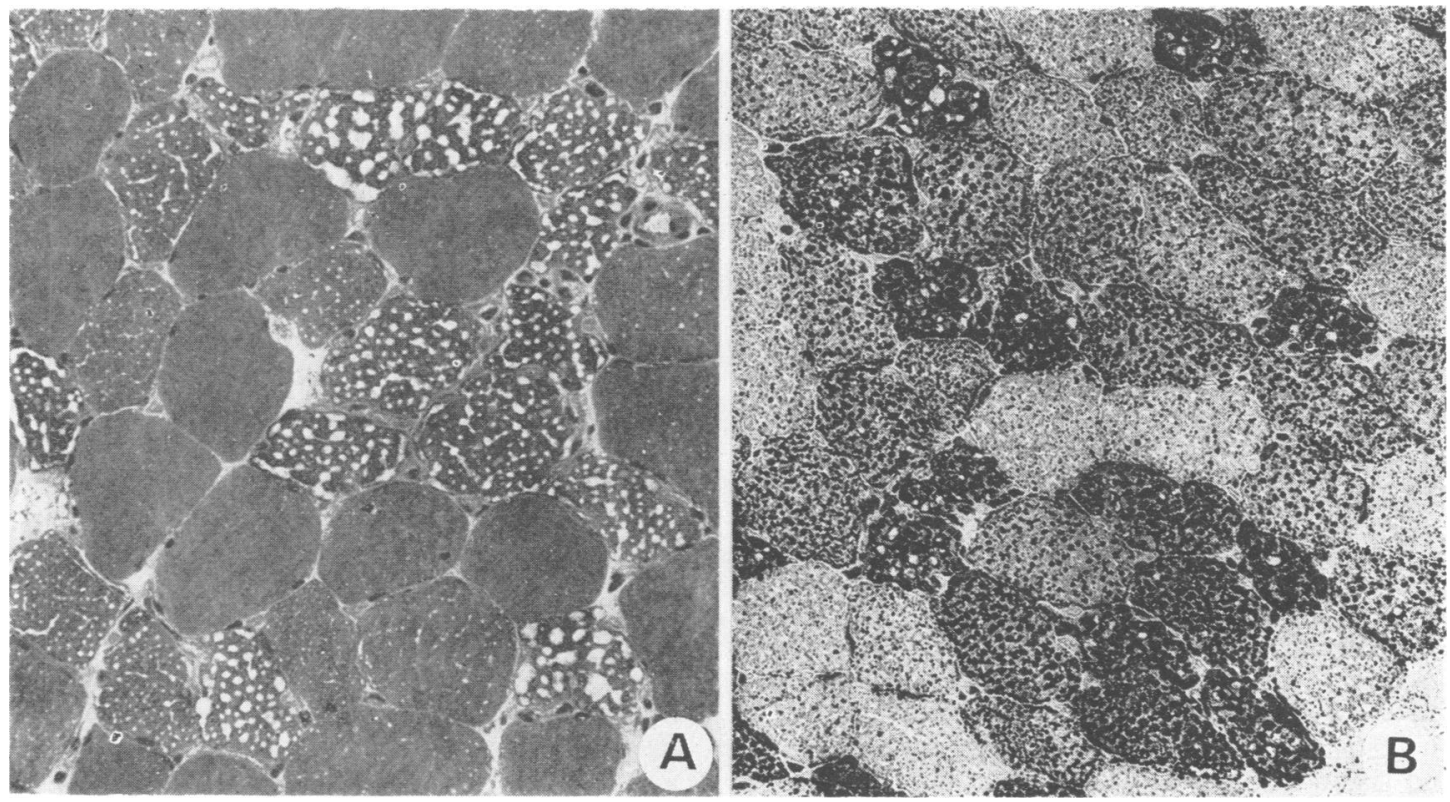

Fig. 1 Case 1. Frozen sections of biopsied deltoid muscle. $\times$ 250. A. Modified Gomori trichrome; many small vacuoles appear in muscle fibres. Some fibres are more affected than others. B. Oil Red $O$; vacuolated fibres contain large amount of neutral lipid.

raised. Urine ketotest was $2+$. The ECG showed clear signs of defective intraventricular conduction, the EMG showed myopathic features, and maximal conduction velocities of $60 \mathrm{~m} / \mathrm{s}$ for the left ulnar and $56 \mathrm{~m} / \mathrm{s}$ for the left peroneal nerves respectively were recorded. With the use of previously described histological and histoenzymatic techniques (Scarlato and Cornelio, 1970), a biopsy of the left deltoid muscle revealed myriads of clear vacuoles (Fig. 1A) that stained positively with ORO (Fig. 1B), limited to type 1 muscle fibres. No other abnormalities were found. A few days after biopsy the patient became weaker, showing a progressively worsening respiratory insufficiency, and died of severe cardiac failure. Permission for necropsy was not obtained.

\section{Case 2}

M.D., an 8 year old boy, was born after full term pregnancy and uneventful delivery from unrelated parents. The only sister of the patient was stated to be a floppy malnourished infant with poor psychomotor development. On admission to another hospital when she was aged 5 years, muscular weakness and wasting together with liver enlargement were noted. She died suddenly two days after being admitted. Blood glucose was $2.8 \mathrm{mmol} / \mathrm{l}$, activities of serum aspartate and alanine aminotransferase, were slightly raised. At post-mortem examination, a diffuse and very severe fatty degeneration of liver, heart, and skeletal muscles was observed, together with extensive degeneration of the motor neurones of the spinal cord.

The proband developed normally until the age $3 \frac{1}{2}$ years, when he experienced an episode of adynamia, nausea, and vomiting together with mental confusion. He was admitted to a country hospital and because of a rise in the blood urea nitrogen (26.6 $\mathrm{mmol} / \mathrm{l}$ ), serum aspartate and alanine aminotransferase (SGOT and SGPT), and LDH activities, a diagnosis of hepatic encephalopathy was made. The EMG showed a myopathic pattern. In a few days the patient fully recovered. Three months later he had a second episode of generalised adynamia, nausea, and vomiting. He was readmitted to the same country hospital. Irregular tremors of the fingers, slight ataxia of the gait, and mental confusion were observed. The blood urea nitrogen was $2.4 \mathrm{mmol} / \mathrm{l}$, SGOT and SGPT were slightly raised, and the urine ketotest was $2+$. Spontaneous remission occurred within a few days. Over the next two years the patient experienced several other episodes of nausea, vomiting, and mental confusion lasting three to four days and developed a progressive proximal muscular weakness. At the age of $5 \frac{1}{2}$ years, he was admitted for the first time to the Institute of Neurology.

The patient was a thin, pale child, with weakness and atrophy of shoulder and pelvic girdles together 
with trunk and neck muscles. Scapular winging, lumbar lordosis, and a waddling gait were noted. Deep tendon reflexes were depressed. The liver was enlarged and palpable two finger breadths below the costal margin. Routine blood analyses were normal, SGOT, SGPT, LDH, and CPK activities were slightly raised. Urine ketotest was $1+$. The EMG showed myopathic features and the maximal motor nerve conduction velocity was within the normal range for the age. Biopsy of the left quadriceps muscle revealed an excess of lipid droplets in type 1 muscle fibres (Fig. 2A), positively staining with ORO (Fig. 2B). No other abnormalities were found. A fasting test performed six months after the first admission induced a marked rise of SGOT, SGPT, LDH, CPK, and aldolase activities after 40 hours of fasting. At this time the blood glucose dropped to 1.7 $\mathrm{mmol} / \mathrm{l}$, urine ketotest was $3+$, and the patient became weak and mentally confused and the test was discontinued. A second biopsy of the left biceps brachii for additional electron microscopic (EM) and biochemical studies was made; the histological and histochemical findings were similar to the previous biopsy. The patient was discharged with a prescription of a carbohydrate-rich diet in which fats were supplied as medium chain triglycerides. One year later there was worsening of muscle weakness and atrophy, but the boy was still capable of attending school and dressing.

The previous therapy was replaced with $2 \mathrm{~g}$ oral $D-L$ carnitine per day, but over the next three months no subjective or objective improvements were noted. At the age of 8 years, while the muscle capacity was only moderately reduced, a sudden coma developed, with undeterminable blood glucose and SGOT, SGPT, CPK, and $\mathrm{K}^{+}$markedly raised; the boy died a few hours after admission.

Necropsy revealed diffuse and severe fatty degeneration of liver, heart, and kidney; skeletal muscles showed an almost complete replacement of type 1 fibres with neutral fat (Fig. 2C). Fragments from kidney and heart were fixed in $\mathrm{PO}_{4}$ buffered $2.5 \%$ gluteraldehyde, postfixed in $\mathrm{OsO}_{4}$, dehydrated and embedded in Epon 812. Semithin sections stained with toluidine blue showed the diffuse presence of large brownish vacuoles, presumably containing lipids, in myocardial fibres (Fig. 3A) and in the epithelial cells of the majority of kidney tubules (Fig. 3B).

\section{Case 3}

P.G., was a 19 years old girl. The clinical history with $\frac{0}{0} \stackrel{\sim}{\circ}$ a complete pathological description of this case has already been described (Cornelio et al., 1975)

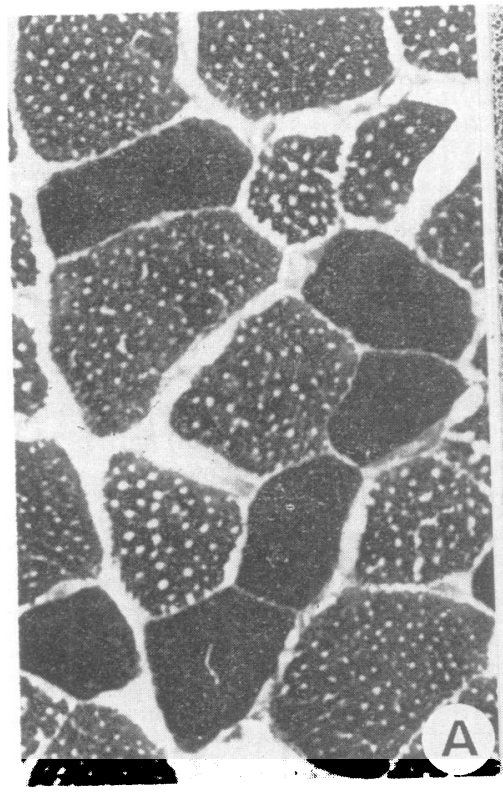

Fig. 2 Case 2. Frozen sections of biopsy specimens $(A$ and $B)$ and necropsy specimen $(C)$ of quadriceps muscle.

A. Myofibrillar ATPase pH 9.4; vacuoles are only in type I fibres. $\times 400$. B. Oil Red O; slight accumulation of lipid in vacuolated fibres. $\times 250$. C. Oil Red $O$; the increase of neutral fat accumulation is evident in comparison with the biopsy specimen. Some fibres appear filled with lipid. $\times 250$. 

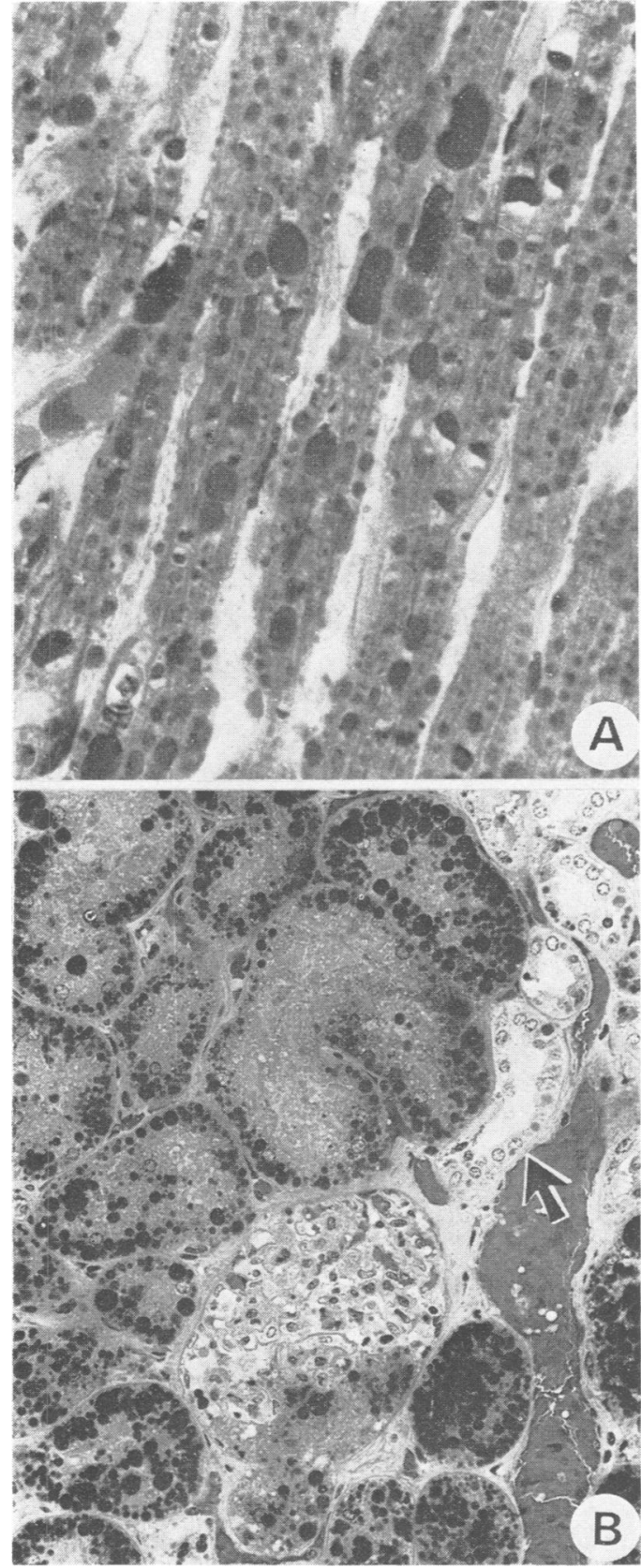

Fig. 3 Case 2. Epoxy resin semithin sections of necropsy specimens. Toluidine-blue. A. Myocardium: myriads of large brownish vacuoles presumably containing lipids are present in myocardial fibres. $\times 400$. B. Kidney: kidney tubules appear markedly degenerated, filled with necrotic material and large brownish drops. Some tubules are apparenily' spared(arrow). $\times 250$.
Briefly, this patient developed, at the age of 16 years, a proximal myopathy preceded by episodes of adynamia, nausea, and vomiting, with an excess of lipid droplets in type 1 fibres, detected at muscle biopsy. The patient died suddenly at age 19 years. Necropsy revealed a striking triglyceride accumulation in skeletal muscles, heart, liver and kidney.

\section{SPECIAL STUDIES}

\section{Electron microscopy}

A fragment of the muscle biopsy obtained with a Pennington haemostatic clamp (Vick and Olson, 1970) was immersed at the bedside in $\mathrm{pH} 7.3,0.1 \mathrm{M}$ phosphate buffered, $4 \%$ gluteraldehyde (Fisher). After 30 minutes' fixation in the clamp, the nontraumatised middle portion of the tissue was trimmed in $1 \mathrm{~mm}$ fragments which were kept in the fixative solution for an additional three hours at room temperature, subsequently washed three times at $4^{\circ} \mathrm{C}$ in $0.1 \mathrm{M}$ phosphate buffer, $\mathrm{pH} 7.3$, postfixed in $2 \%$ buffered $\mathrm{OsO}_{4}$, dehydrated in graded alcohols, and embedded in Epon 812. Thin sections were prepared from selected areas, mounted on coated grids, and stained with uranylacetate and lead citrate. Electron micrographs were taken with a Philips 300 EM apparatus.

The biopsied muscle from the three patients showed a similar ultrastructural pattern. In fact, the prominent abnormality in the muscle fibres was the presence of many rounded spaces, scattered or arranged in parallel rows in longitudinal sections (Fig. 4). The spaces appeared to be empty, or with traces of low density material, and lacked a definite limiting membrane. Sometimes they coalesced to form large, irregularly lobulated vacuoles. The cytoplasm, the myofibrillar material and the sarcoplasmic reticulum were displaced and squeezed by the large empty vacuoles (Fig. 5). The mitochondria were of normal size and shape. In the mitochondrial matrix, larger than usual dense granules were observed. They appeared to be slightly increased in number and most of them were adjacent to the rounded empty spaces.

\section{Biochemistry}

Plasma and biopsied skeletal muscles were assayed for carnitine content by the method described by Marquis and Fritz (1964), while leucocytes and necropsy samples of skeletal muscles, heart, liver, and kidneys were assayed by the radiochemical method of Cederbland and Lindstedt (1972). Total lipid content in tissues was estimated by the procedure of Folch $e t$ al. (1957); qualitative lipid analysis was performed by thin layer chromatography according to O'Brien and Rouse (1964). Acid and alkaline lipase activities in necropsy specimens of skeletal muscles and liver were 


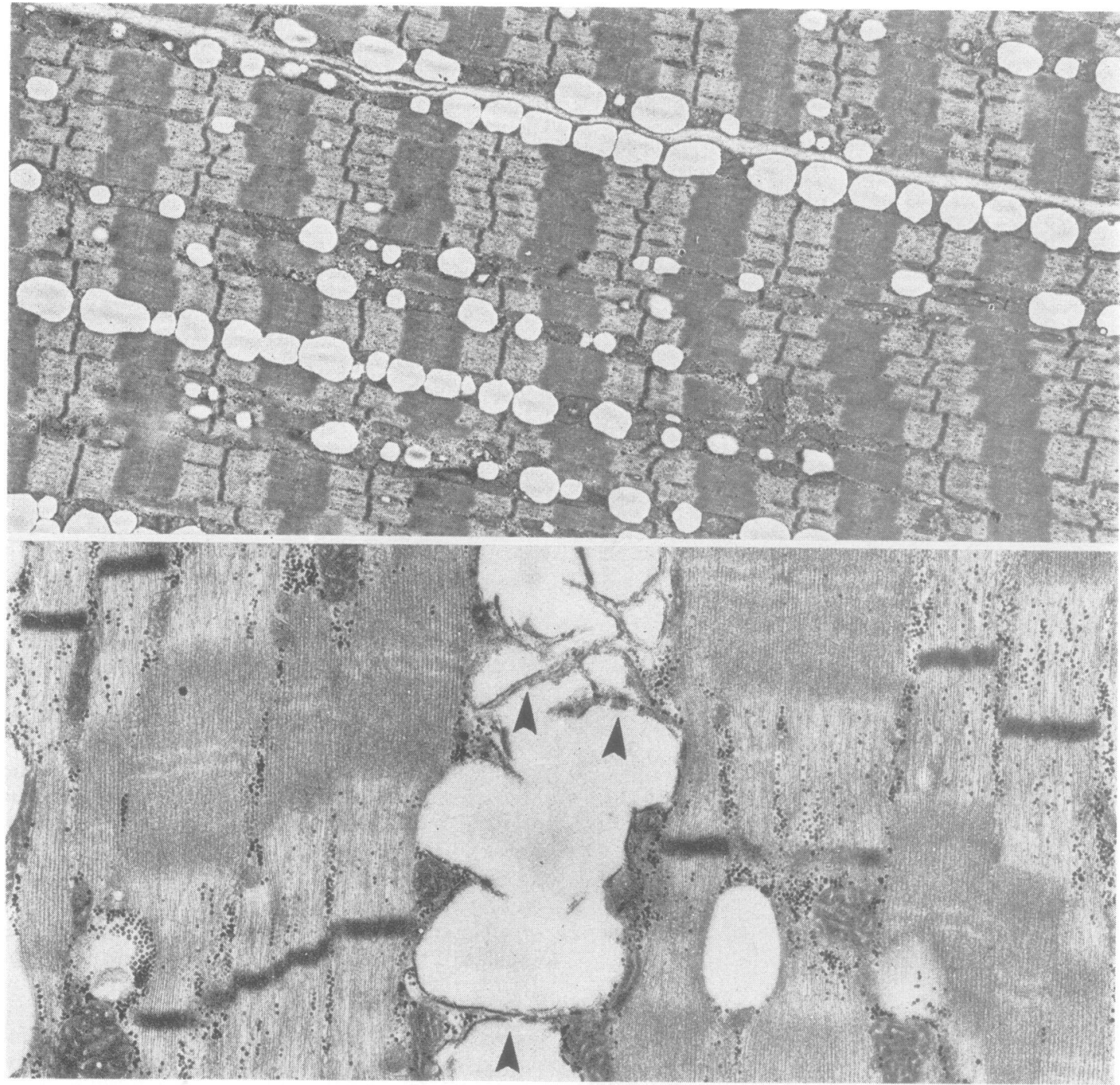

Fig. 4 (Top) Case 2. Quadriceps muscle biopsy. This electron micrograph of longitudinally oriented fibres shows many rounded spaces scattered or arrayed in parallel rows. The vacuoles appear empty or contain traces of low density material. $\times 12000$.

Fig. 5 (Bottom) Case 1. Deltoid muscle biopsy. Sometimes the cytoplasm and the myofibrils are displaced by large, coalescing vacuoles (arrow heads). The mitochondria appear to be normal. $\times 35000$.

determined with the method of Mahadevan and Tappel (1968), using nitrophenyl laurate and p-nitrophenyl palmitate (Sigma, Co., Saint Louis, Missouri, USA) as substrates. Protein was determined with the method of Lowry et al. (1951). Non-collagen protein (NCP) was determined with the method of Lilienthal et al. (1950).

Table 1 shows that the organs of patients 2 and 3 obtained at necropsy had a marked lipid accumula- tion, total lipid content in the muscles being 2.5-3.5 times higher than in the non-myopathic controls of similar age group. The heart and kidneys of patients 2 and 3 contained approximately two and three times higher quantities of total lipids than normal; however, in both cases, lipid accumulation was highest in the liver, the lipid content in this organ being seven and eleven times greater than in our series of nonmyopathic necropsy controls. On the other hand, no 
Table 1 Total lipid content in necropsy sampled organs of patients and non-myopathic controls

\begin{tabular}{llrr}
\hline Organ (necropsy) & Non-myopathic controls & \multicolumn{2}{l}{ Case } \\
\cline { 3 - 4 } & & 2 & 3 \\
\hline Skeletal muscle & & & \\
$\quad$ Pectoral & $3.1 \pm 0.7$ & 7.3 & - \\
$\quad$ Iliopsoas & $1.8 \pm 0.2$ & - & 6.6 \\
Heart & $3.0 \pm 0.2$ & 6.2 & 6.0 \\
Kidney & $2.5 \pm 0.3$ & 9.1 & 9.0 \\
Liver & $3.9 \pm 0.3$ & 43.0 & 27.0 \\
Brain & $3.6 \pm 0.3$ & 3.5 & 3.1 \\
\hline
\end{tabular}

Values are expressed as $\mathrm{mg}$ lipid/100 $\mathrm{mg}$ wet weight.

abnormal lipid accumulation was observed in the brains of our patients. Thin layer chromatography showed that the accumulated lipids were essentially triglycerides and to a lesser extent diglycerides and free fatty acids (FFA). The liver and skeletal muscle acid lipase activity ( $\mathrm{pH} 4.0$ ) was in the same range in patients and controls. Alkaline ( $\mathrm{pH}$ 8.0) lipase activity was in the normal range in patients' liver but in patients' skeletal muscle it was $230 \%$ of the controls.

Plasma and leucocyte carnitine levels are presented in Table 2. Plasma carnitine was only $25 \%$ of normal mean values in patient 3 and $40 \%$ in patient 2 , rising in the latter to $70 \%$ of normal mean values after two months of treatment with $2 \mathrm{~g}$ oral D-L carnitine per day. The parents of patient 2 showed plasma carnitine levels which were approximately $65 \%$ of normal mean values. Leucocyte carnitine was in the same range in patients 2 and 3 and in controls. Plasma and leucocyte carnitine determinations could not be performed in patient 1 .

In the biopsied muscles, carnitine was $10 \%$ of normal mean values in patient 3 and $25 \%$ in patients 1 and 2 . In the post-mortem muscles from patients 2 and 3, carnitine was estimated at between $20 \%$ and $30 \%$ of normal mean values, exhibiting slight differences in the different muscles.
Table 3 Carnitine levels in necropsy sampled organs of patients and non-myopathic controls

\begin{tabular}{llll}
\hline Organ (at necropsy) & Non-myopathic controls & \multicolumn{2}{l}{ Case } \\
\cline { 3 - 4 } & & 2 & 3 \\
\hline Heart & & 2.3 & 2.0 \\
Liver & $6.0 \pm 2.0$ & 4.6 & 5.1 \\
Kidney & $8.3 \pm 2.3$ & 7.7 & 6.5 \\
\hline
\end{tabular}

Carnitine was determined with the radiochemical method and expressed as $\mathrm{nmol} / \mathrm{mg}$.

As shown in Table 3, heart carnitine in patients 2 and 3 was found to be $35 \%$ of controls, liver carnitine was $55 \%$, while kidney carnitine was in the same range of normal values.

\section{Discussion}

Engel et al. (1974) defined as type 1 lipid storage myopathy a syndrome characterised by reduced carnitine levels in muscle and excessive triglycerides in type 1 muscle fibres. In the seven cases so far reported (Engel and Angelini, 1972; Engel et al., 1974; Markesbery et al., 1974; Vandyke et al., 1975; Karpati et al., 1975; Angelini et al., 1975; Smith et al., 1975) the muscular impairment was moderate to severe but only one fatal outcome has been described to date (Engel et al., 1974). In addition beneficial effects of steroids or D-L carnitine replacement therapy were found in the four cases treated. An apparent variant of this syndrome has been described by Karpati et al. (1975) in an 11 year old boy in whom, in addition to muscular triglycerides infiltration, carnitine was decreased in muscle, plasma, and also in the liver, the latter organ being described, however, as otherwise normal at repeated analyses by biopsy. This condition, defined as systemic carnitine deficiency, presented a rela-

Table 2 Plasma, leucocytes and muscle carnitine levels in patients and non-myopathic controls

\begin{tabular}{|c|c|c|c|c|}
\hline \multirow[t]{2}{*}{ Subjects } & \multirow[t]{2}{*}{ Plasma $(\mathrm{nmol} / \mathrm{ml})$} & \multirow[t]{2}{*}{ Leucocvtes* $(\mathrm{nmol} / \mathrm{ml})$} & \multicolumn{2}{|l|}{ Muscle } \\
\hline & & & At biopsy (nmol/mg NCP) & $\begin{array}{l}\text { At necropsyt } \\
(\text { nmol/mg NCP) }\end{array}$ \\
\hline $\begin{array}{l}\text { Non-myopathic controls } \\
\text { Patient } 1 \\
\text { Patient } 2\end{array}$ & $\begin{array}{l}57.9 \pm 12.0 \\
24.7\end{array}$ & $\frac{2.5}{2.2}+0.8$ & $\begin{array}{l}16.0 \pm 2.6 \\
4.0 \text { (deltoid) } \\
3.9 \text { (biceps brachii) }\end{array}$ & $\begin{array}{l}19.0 \pm 6.3 \\
-5.7 \text { (pectoral) } \\
4.2 \text { (iliopsoas) } \\
3.9 \text { (diaphragm) }\end{array}$ \\
\hline $\begin{array}{l}\text { Patient } 2 \text { after carnitine therapy } \\
\text { Patient } 2 \text { (mother) } \\
\text { Patient } 2 \text { (father) } \\
\text { Patient } 3\end{array}$ & $\begin{array}{l}39.0 \\
35.8 \\
39.2 \\
14.8\end{array}$ & $\begin{array}{l}2.4 \\
1.8 \\
2.4 \\
2.6\end{array}$ & $\overline{-}-\overline{1.5 \text { (biceps brachii) }}$ & $\begin{array}{l}- \\
- \\
4.1 \text { (iliopsoas) } \\
3.9 \text { (diaphragm) }\end{array}$ \\
\hline
\end{tabular}

*Values are referred as $\mathrm{nmol} / \mathrm{ml}$ of packed leucocytes prepared with the method of Kampine et al. (1966). Variations of the protein content do not exceed $20 \%$.

+Carnitine was determined with the radiochemical method. 
tively benign course after treatment with oral carnitine.

In comparison with the previously reported cases of lipid storage myopathy and carnitine deficiency, similar and distinctive clinicopathological features could be recognised in our patients.

Both the histochemical and ultrastructural characteristics of the muscle fibres involved as well as the muscular carnitine reduction observed in our three patients are qualitatively and quantitatively comparable with those previously described by Engel and Angelini and other groups (Markesbery et al., 1974; Angelini et al., 1975; Karpati et al., 1975; Vandyke et al., 1975). The clinical course was reminiscent of that reported by Karpati et al. (1975) in their case; in fact, all our cases presented a 'premyopathic phase' apparently lasting from two to 10 years and essentially characterised by recurrent, spontaneous episodes of profound asthenia and adynamia, anorexia, nausea, and vomiting with occasional stupors. In this period, evidence of liver dysfunction was present as indicated, for instance, by a clear hepatomegaly and abnormal levels of serum aspartate and alanine aminotransferases. A similar hepatic impairment was present in Karpati's patient who also presented episodes of 'hepatic encephalopathy' before the recognition of overt muscular deficiency. The myopathy subsequently appearing in our patients was rapidly progressive and could be interpreted as the main cause of death only in one case, whereas, in the two others, death occurred while muscular capacity was only moderately reduced and as a result of an apparent acute metabolic disturbance. No such biphasic pattern has been described for typical type 1 lipid storage myopathy.

The marked triglyceride accumulation in the viscera seen in the two patients of ours submitted to necropsy, does not necessarily constitute a distinction from systemic carnitine deficiency as described by Karpati et al. (1975); two liver biopsies in their patient were described, indeed, as showing an essentially normal picture. Considering, in fact, that triglycerides accumulation with characteristics similar to those seen in our necropsy material can be seen in the dog within 24 hours of an excessive FFA mobilisation induced by noradrenaline infusion (Wirsen, 1965) it is possible that our findings represent only a terminal event. Thus the main difference between ours and Karpati's patient could be only in the severity of the disease. This reasoning could be supported, moreover, by the responsiveness to carnitine replacement and the limited number of 'metabolic' premyopathic episodes in Karpati's case in contrast with the high numbers of such episodes in the clinical history of our patients. However, it has also to be noted that in Karpati's case liver carnitine was markedly reduced, whereas in the two cases tested of this series liver carnitine levels were not significantly decreased in respect to normal.

Wolman disease, in which triglycerides accumulate in visceral organs and in skeletal muscle (Sloan and Fredrickson, 1972) can be differentiated from our cases because of the different clinical picture, the accumulation of cholesterol esters together with triglycerides. In addition, normal levels of acid lipase in muscles and liver were found in our patients 2 and 3.

Neutral lipid storage disease described by Chanarin et al. (1975) is characterised by a neutral lipid storage in the jejunal mucosa, glandular cells of the stomach, liver, skeletal muscles, and leucocytes. Clinically, the only patient described had ichthyosis and EMG signs of myopathy but without muscular weakness. Plasma carnitine content was normal but carnitine was not determined in tissues. A progressive triglyceride accumulation was seen in cultured fibroblasts (Slavin et al., 1975). Skin fibroblasts obtained from our patient 2, however, had normal appearance, could oxidise long chain and medium chain fatty acids normally and their carnitine content was also normal (Di Donato and Cornelio, 1975).

The basic mechanism of the triglyceride accumulation observed in the viscera is still unsolved. Noo correlation between the extent of lipid accumu lation in liver and kidney and the total organ carnitine levels was apparent in our cases; on the other hand, in Karpati's case a profound and apparently stable liver carnitine reduction was associated with a reported normal hepatic structure. In the only. patient of ours in whom carnitine therapy was performed, in spite of an almost normal level of circulating carnitine and stable muscle content of this substance, lipid infiltration became more intense, suggesting that mere carnitine deficiency may not represent the crucial determinant of lipid accumulation. A triglyceride infiltration in viscera exhibiting close topographical and histological similarities with that observed in our two patients who came to necropsy is an essential feature of Reye's syndrome (Brown and Madge, 1975), a condition in which increased circulating FFA characteristically occur in the acute phase (Pollack et al., 1975). No data on carnitine levels in these patients are available.

A marked rise in serum FFA with the development of marked adynamia, nausea, vomiting, and a rise in SGOT, SGPT, LDH, and CPK activitiesthat is, an episode resembling those recorded in her clinical history-was seen in patient 3 when she was forced to use lipids as the prominent energy source as obtained with a fat-rich meal after a fasting period (Cornelio et al., 1975). In the same test conditions 
analogous symptoms were observed also in patient 2 , in whom, however, the determination of FFA could not be performed.

Abnormal levels of FFA have not yet been described in patients with muscular or generalised carnitine deficiency. Whether in our patients, in addition to an impairment of peripheral FFA utilisation, there was also an abnormal mobilisation of FFA cannot be decided at the present time.

Although not formally proven, the inherited nature of the condition described is suggested by the fact that all our cases originated from a restricted mountain area in Northern Italy where consanguineous marriages were relatively frequent in the past. It may also be of interest to note that the one sister of patient 2 succumbed to a condition clinically similar to that presented by this proband.

We thank Mr S. Daniel, Dr M. Rimoldi, and Miss M. Moro for their excellent technical assistance. We are grateful to Dr F. Spreafico for many helpful suggestions with regard to the manuscript.

\section{References}

Angelini, C., Pierobon, S., Lucke, S., and Cantarutti, F. (1975). Carnitine deficiency, Report of a treated case (Abstract-Meeting of American Academy of Neurology). Neurology (Minneap.), 25, 374.

Bradley, W. G., Hudgson, P., Gardner-Medwin, D., and Walton, J. N. (1969). Myopathy associated with abnormal lipid metabolism in skeletal muscle. Lancet, $\mathbf{1}$, 495-498.

Brown, R. E., and Madge, G. E. (1975). The pathology of Reye's syndrome. An overview. In Reye's Syndrome, pp. 77-92. Edited by J. D. Pollack. Grune and Stratton: New York.

Cederblad, G , and Lindstedt, S. (1972). A method for the determination of carnitine in the picomole range. Clinica Chimica Acta, 37, 235-243.

Chanarin, I., Patel, A., Slavin, G., Wills, E. J., Andrews, T. M., and Stewart, G. (1975). Neutral lipid storage disease. British Medical Journal, 1, 553-555.

Cornelio, F., Allegranza, A., Bizzi, A., Cescon, I., Mussini, E., and Peluchetti, D. (1975). Lipidose généralisée a triglycérides (triglycéridose). Première contribution anatomo-clinique. Revue Neurologique, 131, 629-644.

Di Donato, S., and Cornelio, F. (1975). The syndrome of carnitine deficiency. Read at the Italian-Scandinavian Neurological Joint Meeting of Società Italiana di Neurologia, Genova 1975. (In press.)

Engel, A. G., and Angelini, C. (1973). Carnitine deficiency of human skeletal muscle with associated lipid storage myopathy: A new syndrome. Science, 179, 899-902.

Engel, A. G., Angelini, C., Nelson, R. A. (1974). Identification of carnitine deficiency as a cause of human lipid storage myopathy. In Exploratory Concepts: II. Control Mechanisms in Development and Function of Muscle, pp 601-617. Edited by A. T. Milhorat. Excerpta Medica: Amsterdam.

Engel, W. K., Vick, N. A., and Glueck, C. J. (1970). A skeletal-muscle disorder associated with intermittent symptoms and a possible defect of lipid metabolism. New England Journal of Medicine, 282, 697-704.

Folch, J., Lees, M., Sloane, G., and Stanley, G. M. (1957). A simple method for the isolation and purification of total lipids from animal tissues. Journal of Biological Chemistry, 226, 497-508.

Fritz, J. B. (1967). Carnitine in the metabolic control. Perspectives in Biology and Medicine, 10, 643-677.

Kampine, J. P., Brady, R. O., and Kanfer, J. N. (1966). Diagnosis of Gaucher's disease and Niemann-Pick disease with small samples of venous blood. Science, 155, 86-87.

Karpati, G., Carpenter, S., Engel, A. G., Watterns, G., Allen, G., Rothman, S., Klassen, G., and Mamer, O. A. (1975). The syndrome of systemic carnitine deficiency. Neurology (Minneap.), 25, 16-24.

Lilienthal, J. L., Zierler, K. L., Folk, B. P., Buka, R., and Riley, M. J. (1950). A reference base and system for analysis of muscle constituents. Journal of Biological Chemistry, 182, 501-508.

Lowry, O. H., Rosebrough, N. J., Farr, A. L., and Randall, R. J. (1951). Protein measurement with the Folin phenol reagent. Journal of Biological Chemistry, 193, 265-275.

Mahadevan, S. and Tappel, A. L. (1968). Hydrolysis of higher fatty acid esters of p-nitrophenol by rat liver and kidney lysosomes. Archives of Biochemistry and Biophysics, 126, 945-953.

Markesbery, W. R., McQuillen, M. P., Procopis, P. G., Harrison, A. R., and Engel, A. G. (1974). Muscle carnitine deficiency. Archives of Neurology (Chic.), 31, 320-324.

Marquis, N. R., and Fritz, I. B. (1964). Enzymological determination of free carnitine concentration in rat tissues. Journal of Lipid Research, 5, 184-187.

O'Brien, J. S., and Rouse, G. (1964). Analysis of hydroxy fatty acids by gas-liquid chromatography. Analytical Biochemistry, 7, 288-296.

Pollack, J. D., Cramblett, H. G., Flynn, D., and Clark, D. (1975). Serum and tissue lipids in Reye's Syndrome. In Reye's Syndrome, pp. 227-244. Grune and Stratton: New York.

Scarlato, G., and Cornelio, F. (1970). Histochemical correlation in some neuromuscular disorder. In Muscle Diseases, pp. 33-41. Edited by J. N. Walton, N. Canal, and G. Scarlato. Excerpta Medica: Amsterdam.

Slavin, G., Wills, E. J., Richmond, J. E., Chanarin, I., Andrews, T., and Stewart, G. (1975). Morphological features in a neutral lipid storage disease. Journal of Clinical Pathology, 28, 701-710.

Sloan, H. R., and Fredrickson, D. S. (1972). Rare familial disease with neutral lipid storage. In The Metabolic Basis of Inherited Disease, pp. 808-832. Edited by J. B. Stanbury, J. B. Wyngaarden, and D. S. Fredrickson. McGraw Hill: New York.

Smith, D. P. L., Lake, B. D., MacDermot, J., and Wilson, J. (1975). Inborn error of carnitine metabolism ("carnitine deficiency") in man. Lancet, 1, 1198-1199. 
Wirsen, C. (1965). Studies in lipid mobilization. Acta Physiologica Scandinavica, 65, suppl. 252, 1-42.

Vandyke, D. H., Griggs, R. C., Markesbery, W. R., and Di Mauro, S. (1975). Hereditary carnitine deficiency of muscle. Neurology (Minneap.), 25, 154-159.
Vick, N. A., and Olson, W. H. (1970). A biopsy clamp for removal and fixation of muscle in electron microscopy. Stain Technology, 45, 1 . 